\title{
Lipid metabolites of the phospholipase
} $\mathrm{A}_{2}$ pathway and inflammatory cytokines are associated with brain volume in paediatric cerebral malaria

\author{
Vasiliki Pappa', Karl Seydel ${ }^{2,3}$, Sanchit Gupta ${ }^{4}$, Catherine M. Feintuch' ${ }^{1}$, Michael J. Potchen ${ }^{5,6}$, \\ Samuel Kampondeni ${ }^{2}$, Adam Goldman-Yassen ${ }^{4}$, Mike Veenstra ${ }^{7}$, Lillie Lopez ${ }^{7}$, Ryung S. Kim ${ }^{8}$, Joan W. Berman ${ }^{1,7}$, \\ Terrie Taylor ${ }^{2,3}$ and Johanna P. Daily ${ }^{1,4^{*}}$
}

\begin{abstract}
Background: Cerebral malaria (CM) remains a significant cause of morbidity and mortality in children in sub-Saharan Africa. CM mortality has been associated with increased brain volume, seen on neuroimaging studies.

Methods: To examine the potential role of blood metabolites and inflammatory mediators in increased brain volume in Malawian children with CM, an association study was performed between plasma metabolites, cytokine levels and phospholipase $\mathrm{A}_{2}\left(P\left\llcorner\mathrm{~A}_{2}\right)\right.$ activity with brain volume.

Results: The metabolomics analysis demonstrated arachidonic acid and other lysophospholipids to be positively associated with brain swelling. These lipids are products of the PLA $\mathrm{A}_{2}$ enzyme and an association of plasma PLA enzymatic activity with brain swelling was confirmed. TNFa, which can upregulate PLA $A_{2}$ activity, was associated with brain volume. In addition, CCL2 and IL-8 were also associated with brain volume. Some of these cytokines can alter endothelial cell tight junction proteins and increase blood brain barrier permeability.

Conclusions: Taken together, paediatric CM brain volume was associated with products of the $P L A_{2}$ pathway and inflammatory cytokines. Their role in causality is unknown. These molecules will need to undergo testing in vitro and in animal models to understand their role in processes of increased brain volume. These observations provide novel data on host physiology associated with paediatric CM brain swelling, and may both inform pathogenesis models and suggest adjunct therapies that could improve the morbidity and mortality associated with paediatric CM.
\end{abstract}

Keywords: Plasmodium falciparum, Cerebral malaria, Brain swelling, Inflammation, Phospholipase A $_{2}$, Plasma small molecules, Cytokines

\section{Background}

Infection with Plasmodium falciparum remains prevalent in many areas of the world and is associated with severe disease and mortality, particularly in children living in sub-Saharan Africa [1]. Cerebral malaria (CM) is a severe disease syndrome with mortality rates ranging from 15 to

\footnotetext{
*Correspondence: johanna.daily@einstein.yu.edu

${ }^{4}$ Department of Medicine (Infectious Diseases), Albert Einstein College

of Medicine, Bronx, NY 10461, USA

Full list of author information is available at the end of the article
}

$25 \%$ in research settings [2]. In addition, almost a third of paediatric CM survivors develop long-term neurological complications [2, 3]. Severe brain swelling seen on neuroimaging has been reported in paediatric CM. CM associated brain swelling is associated with poor outcomes in Kenyan children and is a significant predictor of mortality in Malawian children [4-6]. Recently, CM associated brain swelling determined by magnetic resonance imaging (MRI) found that swelling in survivors was readily reversible and that mortality was not associated with peripheral parasitaemia [5]. These observations have 
provided new insights into $\mathrm{CM}$ related morbidity and mortality and now can potentially inform development of adjuvant therapies to reverse or prevent brain swelling.

The mechanism of CM brain swelling is unknown and likely involves several factors including parasite mediated venous obstruction, increased permeability of the blood brain barrier (BBB), cytotoxic oedema or increased blood flow volume $[5,6]$. Prior evidence of alterations in BBB permeability includes the observation of fibrinogen leakage into the brain [7]. Moreover, a reduction in endothelial cell tight junction proteins, which maintain the integrity of the $\mathrm{BBB}$, has been reported, providing further support for increases in BBB permeability during CM [8-10]. A variety of systemic factors can lead to transient increase of BBB permeability in other diseases. These include the metabolic derangements associated with diabetic ketoacidosis and elevated concentrations of oxidized phospholipids [11, 12]. Systemic metabolic abnormalities are common in CM, which is often associated with a hyperlactataemia, hypoglycaemia and evidence of marked inflammation [13-16]. Therefore, metabolites measured in a cohort of Malawian children with CM were correlated to brain volume, to examine their role as potential mediators of brain swelling.

Arachidonic acid, other phospholipase $\mathrm{A}_{2}\left(\mathrm{PLA}_{2}\right)$ lipid metabolites and plasma $\mathrm{PLA}_{2}$ enzymatic activity were associated with brain swelling. Expression of the PLA enzyme is upregulated via the nuclear factor-kappa $\mathrm{B}(\mathrm{NF \kappa B})$ pathway, which in turn is regulated by proinflammatory cytokines, such as tumour necrosis factor alpha (TNFo) [17]. An association of TNFo and other cytokines with brain swelling was found, suggesting that brain swelling is associated with a high inflammatory state. These data provide new biochemical insights into mechanisms of brain swelling in paediatric CM. Further experiments are needed to determine if these associated molecules induce increased brain swelling in the setting of CM.

\section{Methods}

\section{Study population}

To identify small molecules associated with brain swelling in paediatric $\mathrm{CM}$, correlations were sought, between brain volume and both host factors and plasma metabolites in Malawian children enrolled in an ongoing study of malaria pathogenesis in the Blantyre Malaria Project (BMP) during the 2009, 2011 and 2013 transmission seasons. The BMP study enrolls children with clinically defined CM [2], who are between 6 months and 12 years of age. This analysis was restricted to children who were HIV negative, had negative blood and CSF bacterial cultures and evidence of malaria retinopathy $[18,19]$. The study was restricted to patients with retinopathy positive $\mathrm{CM}$, as the presence of retinal abnormalities increases the specificity of the clinical diagnosis of $\mathrm{CM}$ [18]. Plasma collected from the study subjects on admission, was stored at $-80^{\circ} \mathrm{C}$ and shipped to Albert Einstein College of Medicine in a liquid nitrogen dry shipper for subsequent metabolic and cytokine profiling. Plasma histidine rich protein 2 (HRP2), a parasite protein that represents total body parasite burden [20], was measured using ELISA, as previously described [21]. Clinical and laboratory data were extracted from the study database. Informed consent was obtained from the parent or guardian before enrollment into the BMP. This study was approved by the Albert Einstein College of Medicine Institutional Review Board (IRB), Michigan State University IRB, the University of Rochester IRB, and The University of Malawi College of Medicine Research and Ethics Committee.

\section{Neuroimaging}

Neuroimaging was used to assess brain swelling with a 0.35T Signa Ovation Excite MRI scanner (GE Healthcare, Milwaukee, Wisconsin). The scans were read independently by two radiologists as previously reported $[5,6$, 22]. Patient brain volume score was assigned based on a consensus interpretation of both radiologists. Brain volume was measured using a 1-8 scoring system, 1 and 2 indicating atrophy, 3-normal brain volume, 4-slightly increased brain volume, 5-mildly increased brain volume, 6-moderately increased brain volume, defined as loss of some sulcal markings, 7-moderately/severely increased brain volume with diffuse sulcal and cisternal effacement universally evident but without herniation present, and 8-severely increased brain volume with the findings of 7 and with evidence of herniation.

\section{Plasma cytokine quantification}

Plasma cytokine data were available from a prior study (Feintuch, C.M. personal communication) for patients from 2009 and 2011. Cytokine levels were assessed by Luminex using the Human Cytokine Panel according to manufacturer's instructions (Millipore) and read on a Magpix Multiplex Reader (Luminex).

\section{Metabolomics}

Global non-targeted MS metabolomics analysis was performed at Metabolon, Inc. from $100 \mu \mathrm{L}$ of plasma [23]. This method uses ultra-high performance liquid chromatography/tandem mass spectrometry in both positive and negative ion modes along with gas chromatography/ mass spectrometry to maximize compound detection and accuracy. Metabolites were identified by comparing the spectral signatures of the plasma samples to a reference library using software developed at Metabolon [24]. 


\section{Plasma PLA $\mathrm{A}_{\mathbf{2}}$ activity fluorescence assay}

To measure plasma PLA ${ }_{2}$ activity, a PLA $\mathrm{PL}_{2}$ fluorescence assay was performed as previously described with minor modifications [25]. Briefly, the liposomes were prepared with $2 \mathrm{mg}$ of PG (L- $\alpha$-Phosphatidyl-DL-glycerol sodium, Sigma) mixed with $14 \mu \mathrm{g}$ of Red/Green BODIPY ${ }^{\circledR}$ PC-A (1-O-(6-BODIPY ${ }^{\circledR}$ 558/568-aminohexyl)-2-BODIPY ${ }^{\circledR} \quad$ FL $\mathrm{C}_{5}$-sn-glycero-3-phosphocholine, Life Technologies) in $1 \mathrm{ml}$ of chloroform, which was subsequently evaporated under argon. The liposomes were added in $1 \mathrm{ml}$ of $(250 \mathrm{mM}$ sucrose, $50 \mathrm{mM}$ Tris- $\mathrm{HCl} \mathrm{pH} 7.5$ and $0.02 \%$ sodium azide) and the mixture was vortexed for $20 \mathrm{~min}$ and sonicated 6 times for $30 \mathrm{~s}$ with $1 \mathrm{~min}$ intervals on ice. The liposomes were then aliquoted in smaller quantities, stored in $-20{ }^{\circ} \mathrm{C}$ and used within 30 days of preparation. For each sample $3 \mu \mathrm{l}$ of patient plasma were mixed with $97 \mu \mathrm{l}$ of $\mathrm{PLA}_{2}$ assay buffer $\left(10 \mathrm{mM}\right.$ Tris- $\mathrm{HCl}$, pH 7.5 and $\left.10 \mathrm{mM} \mathrm{CaCl}_{2}\right)$ into a black assay plate (Corning). Subsequently, $1 \mu \mathrm{l}$ of fluorescent

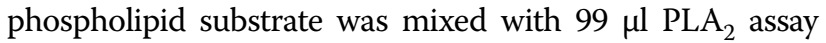
buffer, sonicated for $10 \mathrm{~s}$ and added to the assay plate for a final volume of $200 \mu \mathrm{l}$. The plate was shaken for $15 \mathrm{~s}$, incubated at $37^{\circ} \mathrm{C}$ for $30 \mathrm{~min}$ and fluorescence was recorded at $470 \mathrm{~nm}$ excitation and $515 \mathrm{~nm}$ emission (BioTek). Samples were run in triplicate and the mean values of the relative fluorescence units (RFUs) at $30 \mathrm{~min}$ are reported.

\section{Statistical analysis}

To determine whether age, vital signs, HRP2, peripheral parasitaemia, plasma cytokines, complete blood count on admission, or coma resolution time correlated with brain volume, Spearman's correlations were used. Two sided p-values $<0.05$ were considered statistically significant.

For the metabolomics analysis, ion counts were generated for each metabolite. A maximum likelihood method was used to impute left-truncated abundance values for each metabolite [26, 27]. First the mean and variance of the log transformed abundance values was estimated for each metabolite. Then the expectation of the left-truncated normal distribution of each metabolite was used to impute censored values. Spearman's correlations were then performed between each metabolite or clinical factor and brain swelling scores.

The mean plasma PLA 2 RFU values at 30 min of incubation were $\log 10$ transformed. Spearman's correlations on the plasma PLA $\mathrm{P}_{2}$ activity were then carried out and brain volume scores with $\mathrm{p}<0.05$ were considered statistically significant. The correlations were performed using Graph Pad Prism 6.03 (GraphPad Software, San Diego, CA, USA).

\section{Results}

\section{Study population}

Fifty-three Malawian children with retinopathy positive $\mathrm{CM}$, who were enrolled in the BMP cohort during the transmission seasons 2009, 2011, and 2013, and had available plasma and neuro-imagining data were studied. Seven (13\%) children had a volume score of 3; eight (15\%) children had a volume score of 4; eleven (21\%) children had a volume score of 5 ; thirteen (25\%) children had a volume score of 6 ; and fourteen (26\%) children had a volume score of 7 . The cohort had a median age of 52 months, haematocrit of $21.2 \%$, coma resolution time of $48 \mathrm{~h}$, and $17 \%$ mortality (Table 1 ). There were no statistically significant correlations between age, coma resolution time, vital signs, blood counts, peripheral parasitaemia or HRP2 concentration, measured on admission with brain swelling (Table 1) [5].

\section{Metabolite correlation with brain volume}

To identify plasma small molecules associated with CM brain swelling, a metabolomics analysis was carried out on 30 randomly selected plasma samples from the total study population enrolled in 2011 and 2013. There were no significant differences in the characteristics reported in Table 1 between the metabolomics sub-cohort and the total study population (Additional file 1: Table S1).

Brain volume positively correlated to 17 out of the 432 detected molecules (Spearman's correlation, $\mathrm{p}$ value $<0.05$ ) (Table 2). A wide range of molecules was identified to be

Table 1 Clinical and laboratory data of admission in $\mathbf{5 3}$ children with retinopathy positive $\mathrm{CM}$ and correlation with brain volume

\begin{tabular}{lcll}
\hline Characteristic & Median (IQR) & P-value & Spearman's r \\
\hline Demographics & & & \\
Age (months) & $52(31.5-73)$ & 0.88 & -0.02 \\
Female sex, no (\%) & $28(53)$ & & $\mathrm{NA}$ \\
Clinical findings & & & \\
Temperature $\left({ }^{\circ} \mathrm{C}\right)$ & $38.5(37.6-39.4)$ & 0.70 & 0.05 \\
Blood pressure $(\mathrm{mmHg})$ & $93(87-101)$ & 0.14 & -0.21 \\
Heart rate (beats/min) & $148(129.5-163)$ & 0.58 & 0.08 \\
Respiratory rate (breaths/ & $42(37-52)$ & 0.67 & 0.06 \\
$\quad$ min) & & & \\
Laboratory findings & & & \\
Parasitaemia $($ para- & $69.5(22.0-338.8)$ & 0.62 & 0.07 \\
$\quad$ sites $\left.\times 10^{3} / \mu l\right)$ & $7208(2535-9541)$ & 0.30 & -0.15 \\
HRP2 (ng/ml) & $7.9(6.0-11.0)$ & 0.28 & 0.15 \\
Total WBC $\left(\times 10^{3} / \mu l\right)$ & $61.5(30.8-100.5)$ & 0.67 & -0.08 \\
Platelets $\left(\times 10^{3} / \mu l\right)$ & $21.2(17.9-26.4)$ & 0.41 & 0.12 \\
Hct $(\%)$ & & & \\
Clinical outcome & $48(30-82)$ & 0.42 & 0.13 \\
Coma resolution time $(\mathrm{h})$ & $9(17)$ & & $\mathrm{NA}$ \\
Death, no. $(\%)$ & &
\end{tabular}

Description of patient characteristics and correlation with brain oedema scores. P-values and Spearman's $r$ are shown for continuous variables. IQR: interquartile range 
associated with brain volume, including lipids. Many of the significant lipid metabolites are $\mathrm{PLA}_{2}$ metabolites. PLA is an enzyme that hydrolyzes phospholipids at the sn-2 position, to liberate lysophospholipids and free fatty acids, including arachidonic acid [28]. Brain swelling correlated with the lysophospholipids, 1-eicosatrienoylglycerophosphoethanolamine and 1-oleoylglycerophosphoethanolamine. The fatty acids arachidonic acid and pentadecanoic acid, as well as 5-hydroxyhexanoate, a fatty acid metabolite, were also significantly associated with brain swelling.

L-urobilin, a metabolite of the hemoglobin catabolism pathway, was highly correlated with brain volume. Among other molecules, the carbohydrate, mannitol was also associated with brain swelling (Table 2).

\section{Plasma sPLA 2 activity and CM brain swelling}

Since $\mathrm{PLA}_{2}$ metabolites correlated with brain swelling, the PLA $\mathrm{P}_{2}$ enzymatic activity itself was examined for correlations with brain swelling. To determine PLA 2 activity, a fluorescence $\mathrm{PLA}_{2}$ enzymatic assay was carried out on the same BMP study enrollment plasma samples from all 53 patient samples. A significant correlation of increasing $\mathrm{PLA}_{2}$ activity and brain volume was observed (Spearman's correlation $r=0.31, p$ value $=0.02$ ) (Fig. 1 ).

Table 2 Plasma metabolites associated with brain volume in Malawian children with retinopathy positive CM

\begin{tabular}{|c|c|c|}
\hline Metabolite & P-value & Spearman's r \\
\hline \multicolumn{3}{|l|}{ Lipids associated with the PLA ${ }_{2}$ pathway } \\
\hline Pentadecanoate (15:0) & 0.03 & 0.39 \\
\hline $\begin{array}{l}\text { 1-Eicosatrienoylglycerophosphoethanola- } \\
\text { mine* }^{*}\end{array}$ & 0.04 & 0.38 \\
\hline Arachidonate $(20: 4 n 6)$ & 0.04 & 0.38 \\
\hline 1-Oleoylglycerophosphoethanolamine & 0.05 & 0.37 \\
\hline \multicolumn{3}{|l|}{ Other lipids } \\
\hline Butyrylcarnitine & 0.01 & 0.46 \\
\hline 2-Linoleoylglycerol (2-monolinolein) & 0.02 & 0.42 \\
\hline Octanoylcarnitine & 0.03 & 0.41 \\
\hline 5-Hydroxyhexanoate & 0.04 & 0.37 \\
\hline \multicolumn{3}{|l|}{ Other metabolites } \\
\hline Phenylacetate & 0.00 & 0.52 \\
\hline 1,3,7-trimethylurate & 0.00 & 0.52 \\
\hline Alpha-ketoglutarate & 0.01 & 0.46 \\
\hline Mannitol & 0.01 & 0.45 \\
\hline 3-hydroxy-2-ethylpropionate & 0.02 & 0.43 \\
\hline Paraxanthine & 0.02 & 0.42 \\
\hline Thymol sulfate & 0.04 & 0.38 \\
\hline L-urobilin & 0.04 & 0.37 \\
\hline Sucrose & 0.04 & 0.37 \\
\hline
\end{tabular}

Analysis carried out on from 30 samples collected in 2011 and 2013 are shown ( $p$-value $<0.05$ ). Asterisk represents a metabolite that was identified based on its chromatographic and mass spectra rather than a purified standard

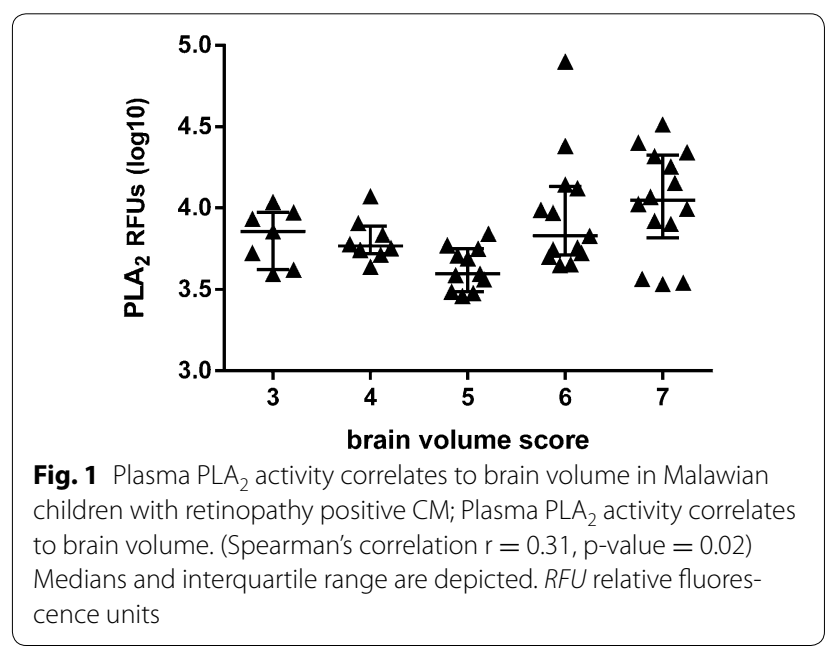

\section{Cytokine activity and CM brain swelling}

The $\mathrm{PLA}_{2}$ pathway and its downstream lipid products, such as arachidonic acid mediate inflammatory responses [29]. PLA 2 can be upregulated by TNF $\alpha$ and thus we examined TNF $\alpha$ and other inflammation related cytokines for their association with CM brain swelling. Cytokine data were available for 27 samples from the total cohort. For this subset of patients, clinical and laboratory data were similar to the total study population (Additional file 1: Table S1). Statistically significant correlations were observed, between brain volume, and TNF $\alpha$ (Spearman's correlation $r=0.38, \mathrm{p}$-value $=0.05$ ), CCL2 (Spearman's correlation $\mathrm{r}=0.44, \mathrm{p}$-value $=0.02$ ), IL-8 (Spearman's correlation $\mathrm{r}=0.43$, $\mathrm{p}$-value $=0.03$ ) and IL-10 (Spearman's correlation $\mathrm{r}=0.50, \mathrm{p}$-value $=0.01$ ) (Fig. 2).

\section{Discussion}

To identify potential mediators of brain swelling associated with paediatric CM, plasma metabolite levels of Malawian children with retinopathy positive CM were correlated to brain volume. Associations were identified between $\mathrm{PLA}_{2}$ metabolites, including arachidonic acid, with brain volume. Plasma $\mathrm{PLA}_{2}$ enzymatic activity also correlated to brain volume, suggesting an upregulation of the $\mathrm{PLA}_{2}$ pathway in children with high brain swelling. TNF $\alpha$ can upregulate $\mathrm{PLA}_{2}$ and this study reports that, in conjunction with other inflammatory cytokines, TNF $\alpha$ is correlated with brain volume. L-urobilin, a haem degradation product and mannitol were also associated with brain volume. Collectively, these results suggest a higher inflammatory state in children with increased brain volume. Further studies on how these molecules may be involved in BBB disruption, and why some children sustain a higher inflammatory state are now warranted. 

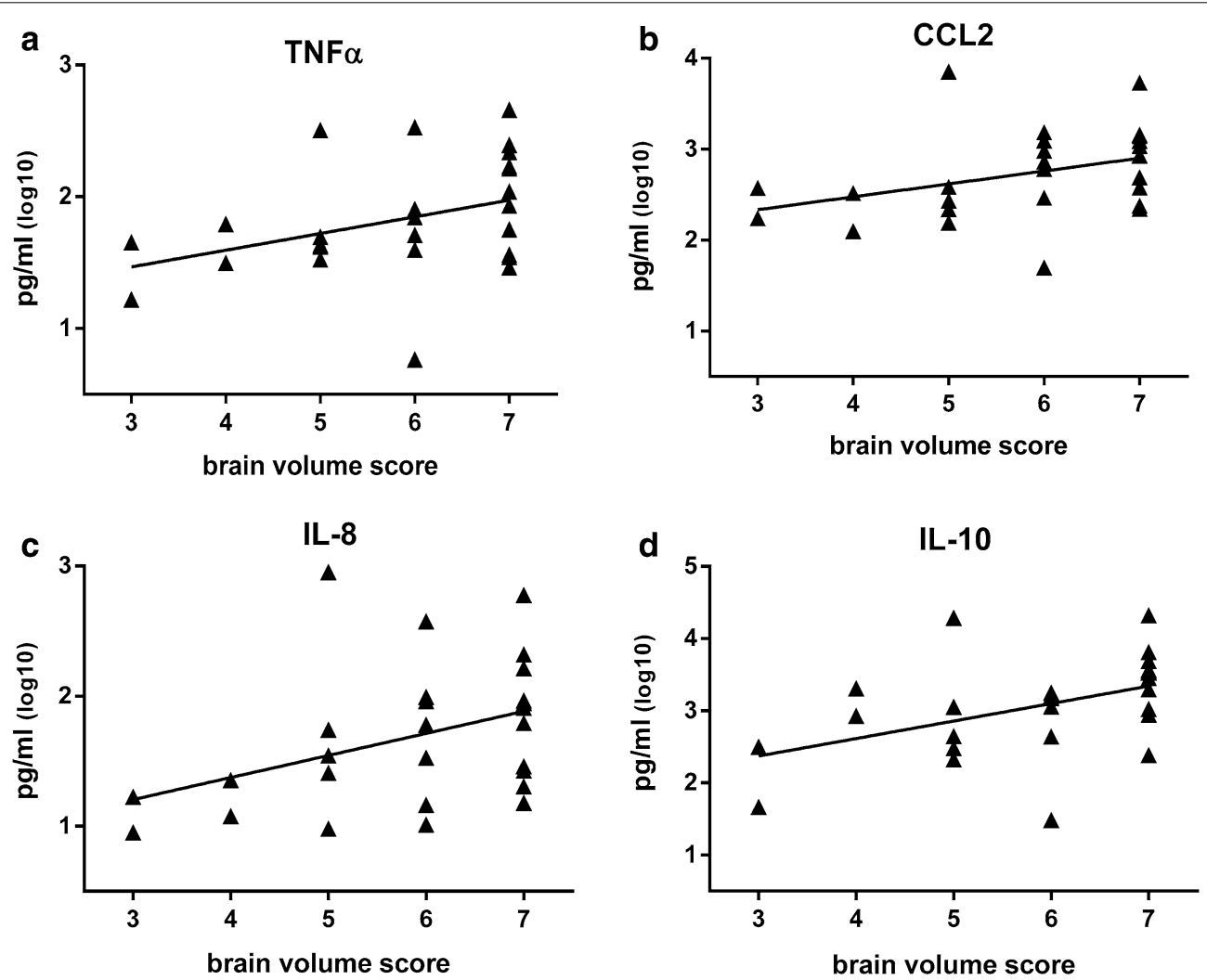

Fig. 2 Cytokines correlate to brain volume in Malawian children with retinopathy positive CM; Multiple cytokines significantly correlate with brain volume. a TNFa levels (Spearman's correlation r, 0.38, p-value $=0.05$ ). b CCL2 levels (Spearman's correlation r, 0.44, $p$-value $=0.02$ ). $\mathbf{c} \| L-8$ levels (Spearman's correlation r, 0.43, $p$-value $=0.03$ ). $\mathbf{d}$ IL-10 levels (Spearman's correlation r: 0.50, $p$-value $=0.01$ ). Cytokines were measured by Luminex in duplicate and the mean value is displayed

Brain swelling has recently been shown to be the strongest predictor of mortality in paediatric CM, with an adjusted odds ratio of 7.5 (95\% CI 2.1-26.9) for severe brain swelling among patients who died compared to those who survived [5]. Brain swelling induces increased intracranial pressure that may lead to brainstem compromise and respiratory arrest. The mechanism of increased brain volume is unknown. Multiple mechanisms of increased brain volume may exist in clinical conditions such as CM [30], including processes that impact $\mathrm{BBB}$ function $[5,7,10]$. This study set out to identify circulating biochemical mediators that may contribute to BBB dysfunction. [7, 10].

Positive correlations between brain volume and several lipids that are $\mathrm{PLA}_{2}$ metabolites were identified. The fatty acids released by $\mathrm{PLA}_{2}$, such as arachidonic acid, can be sources of energy, signaling, and of relevance to this study, potent mediators of inflammation. Specifically, arachidonic acid, the precursor of the eicosanoid pathway, can increase the permeability of human brain microvasculature endothelial cell monolayers via prostaglandin $E_{2}$ activation of $\mathrm{EP}_{3}$ and $\mathrm{EP}_{4}$ receptors [31].
Lysophospholipids are also generated by $\mathrm{PLA}_{2}$ and are important in cell signaling and membrane biology. PLA enzymatic activity has been associated with neurological and inflammatory conditions and inhibitors of the PLA enzyme are being studied to reduce pathologic inflammation [32-36]. Fatty acids and lysophospholipids can be generated by enzymes other than $\mathrm{PLA}_{2}$, therefore it was confirmed in this study that plasma $\mathrm{PLA}_{2}$ activity was also correlated with brain swelling [37, 38]. These data extend a prior observation where high $\mathrm{PLA}_{2}$ plasma activity was associated with severe malaria and death in Malawian children [39]. Why some children have higher $\mathrm{PLA}_{2}$ enzyme activity is unknown. PLA $\mathrm{A}_{2}$ activity is tightly regulated by host responses including TNF $\alpha$ and reactive oxygen species (ROS), both of which can be elevated during severe malaria $[15,40,41]$. Thus the $\mathrm{PLA}_{2}$ pathway and its metabolites may be acting directly on brain microvasculature endothelial cells or indirectly through their effects on cell signaling or energy metabolism.

L-urobilin, a degradation product of haem also correlated with brain volume. Malaria induces erythrocyte lysis and subsequent release of haemoglobin into 
the circulation. This results in increase of bloodstream ROS levels, which can alter BBB permeability [41-44]. Lysed erythrocytes can increase BBB permeability and result in brain oedema, typically occurring twenty-four hours after haemolysis [45-47]. Direct measurement of ROS and other haemoglobin metabolites are needed to explore the role of erythrocyte lysis in CM associated brain swelling.

Plasma mannitol was also found to have a positive correlation with brain swelling. Exogenous mannitol has been associated with increased brain oedema or brain weight in animal models of vasogenic oedema and brain infarct $[50,51]$. Mannitol is used therapeutically for the treatment of increased intracranial pressure following brain injury [48, 49]. Mannitol adjunctive therapy has been studied in CM and was found to either have no significant effect on clinical outcomes in paediatric $\mathrm{CM}$ in Uganda [52] or to potentially have adverse outcomes by prolonging coma resolution time in adults with CM [53]. Further studies to investigate the role of endogenous and exogenous mannitol in CM paediatric brain swelling are necessary.

Inflammatory cytokines were also associated with brain volume and these may directly alter BBB permeability. CCL2 and IL-8 have been previously associated with alterations in tight junction proteins including occludin, ZO-1 and claudin-5 resulting in increased brain endothelial cell permeability $[54,55]$. In addition, TNF $\alpha$ has been shown to increase retinal endothelial cell permeability through protein kinase $\mathrm{C}$ zeta $(\mathrm{PKC} \zeta)$ and the $\mathrm{NFKB}$ pathway by reducing the expression and distribution of claudin-5 and ZO-1 [56]. Interestingly, inhibition of TNF $\alpha$ by soluble TNF p55 receptor attenuates status epilepticus-induced oedema in a rat model, which could be relevant in $\mathrm{CM}$, as seizures are highly prevalent [3, 57]. Furthermore, TNF $\alpha$ can regulate the transcription of $\mathrm{PLA}_{2}$ proteins via the NFKB pathway, providing a link between inflammatory cytokines and the $\mathrm{PLA}_{2}$ pathway [17]. The mechanism, where inflammatory cytokines, increased $\mathrm{PLA}_{2}$ activity and its lipid metabolites converge to disrupt the $\mathrm{BBB}$, in the setting of parasites sequestration to brain endothelial cells in $\mathrm{CM}$, requires further investigation. If the $\mathrm{PLA}_{2}$ pathway is found to play a direct role in $\mathrm{BBB}$ dysfunction, $\mathrm{PLA}_{2}$ inhibitors could be evaluated as potential adjunctive therapy.

The higher inflammation and brain volume do not correlate with peripheral parasitaemia or total parasite body load represented by parasite HRP2 levels [58]. The variability in inflammatory responses during infection could be attributed to differences in disease duration, host or parasite genetic polymorphism, prior malaria exposures, uric acid levels or other host or parasite factors [59-65]. Further studies examining how host and/or parasite parameters are mediating inflammation and upregulation of the PLA $\mathrm{P}_{2}$ pathway in the setting of increased brain volume could inform therapeutic intervention.

A limitation to the design of this study is that the plasma metabolome was examined after onset of brain swelling. For this reason, it is difficult to know if the metabolic profile is a cause of BBB dysfunction or the result of changes secondary to increased brain volume. A longitudinal study design with repeated metabolic sampling over time in correlation to brain swelling status would provide a more powerful approach to identify potential mediators of $\mathrm{BBB}$ permeability. Additionally, there were no metabolomics data from patients with brain volume scores 1, 2 and 8 due to the low prevalence of those brain volume scores. To develop biomarkers of brain swelling for regions without MRI, further plasma analyses that include all of the brain volume groups are warranted. Given the variances observed, larger sample sizes would permit corrections for multiple comparisons.

\section{Conclusions}

This study shows associations between brain volume and plasma PLA ${ }_{2}$ activity, metabolites of the PLA ${ }_{2}$ pathway, inflammatory cytokines, and other molecules in paediatric CM patients. The role of these small molecules and cytokines as disease mediators or drug target candidates can now be further investigated.

\section{Additional file}

Additional file 1: Table S1. Clinical and laboratory data of admission in children with retinopathy positive CM and comparison between subcohorts and total study population.

\section{Abbreviations}

CM: cerebral malaria; PLA 2 : phospholipase $\mathrm{A}_{2}$; TNF: tumour necrosis factor; CCL2: chemokine (C-C motif) ligand 2; lL-8: interleukin 8; MRI: magnetic resonance imaging; BBB: blood brain barrier; BMP: Blantyre Malaria Project; HIV: human immunodeficiency virus; CSF: cerebrospinal fluid; iRBC: infected red blood cell; IRB: Institutional Review Board; MS: mass spectrometry; PG: L-aphosphatidyl-DL-glycerol sodium; Red/Green BODIPY PC-A 2 : 1-O-(6-BODIPY ${ }^{\circledR}$ 558/568-aminohexyl)-2-BODIPY ${ }^{\circledR}$ FL C $_{5}$-sn-glycero-3- phosphocholine; RFU: relative fluorescence unit; IL-10: interleukin 10; ROS: reactive oxygen species; ZO-1: zonula occludens-1; PKCC: protein kinase C zeta; NFkB: nuclear factorkappaB; HRP2: histidine rich protein 2.

\section{Authors' contributions}

VP was involved in study design, cytokine and brain swelling correlation analysis, plasma PLA 2 analysis and manuscript preparation. KS and TT were involved in human study design, and manuscript preparation. SG carried out the metabolomics analysis and contributed in manuscript preparation. CMF was responsible for human sample handling, cytokine levels measurements and manuscript preparation. MP and SK evaluated the neuroimaging data and were involved in manuscript preparation. AG and RSK contributed in data analysis. MV and LL contributed expertise in BBB permeability. JWB contributed BBB permeability expertise and manuscript preparation. JPD was involved in study design, data analysis and manuscript preparation. All authors read and approved the final manuscript. 


\section{Author details}

${ }^{1}$ Department of Microbiology and Immunology, Albert Einstein College of Medicine, Bronx, NY 10461, USA. ${ }^{2}$ Blantyre Malaria Project, University of Malawi College of Medicine, Blantyre, Malawi. ${ }^{3}$ Department of Osteopathic Medical Specialties, College of Osteopathic Medicine, Michigan State University, East Lansing, MI 48824, USA. ${ }^{4}$ Department of Medicine (Infectious Diseases), Albert Einstein College of Medicine, Bronx, NY 10461, USA. ${ }^{5}$ Department of Radiology, University of Rochester, Rochester, NY 14642, USA. ${ }^{6}$ Lusaka Apex Medical University, Medical Radiation Sciences, Lusaka, Zambia. ${ }^{7}$ Department of Pathology, Albert Einstein College of Medicine, Bronx, NY 10461, USA. ${ }^{8}$ Department of Epidemiology and Population Health, Albert Einstein College of Medicine, Bronx, NY 10461, USA.

\section{Acknowledgements}

We thank Neida Mita-Mendoza and Gretchen Birbeck for critical review of the manuscript. This work was supported by Grant R01 Al077623 (to JPD) from the National Institutes of Health.

\section{Competing interests}

The authors declare that they have no competing interests.

Received: 24 June 2015 Accepted: 4 December 2015

Published online: 21 December 2015

\section{References}

1. Murray CJ, Ortblad KF, Guinovart C, Lim SS, Wolock TM, Roberts DA, et al. Global, regional, and national incidence and mortality for HIV, tuberculosis, and malaria during 1990-2013: a systematic analysis for the Global Burden of Disease Study 2013. Lancet. 2014;384:1005-70.

2. WHO: Guidelines for the Treatment of Malaria. Geneva: World Health Organization; 2010.

3. Birbeck GL, Beare N, Lewallen S, Glover SJ, Molyneux ME, Kaplan PW, et al. Identification of malaria retinopathy improves the specificity of the clinical diagnosis of cerebral malaria: findings from a prospective cohort study. Am J Trop Med Hyg. 2010;82:231-4.

4. Newton CR, Peshu N, Kendall B, Kirkham FJ, Sowunmi A, Waruiru C, et al. Brain swelling and ischaemia in Kenyans with cerebral malaria. Arch Dis Child. 1994;70:281-7.

5. Seydel KB, Kampondeni SD, Valim C, Potchen MJ, Milner DA, Muwalo FW et al. Brain swelling and death in children with cerebral malaria. N Engl J Med. 2015;372:1126-37.

6. Potchen MJ, Kampondeni SD, Seydel KB, Birbeck GL, Hammond CA Bradley WG, et al. Acute brain MRI findings in 120 Malawian children with cerebral malaria: new insights into an ancient disease. AJNR Am J Neuroradiol. 2012;33:1740-6.

7. Dorovini-Zis K, Schmidt K, Huynh H, Fu W, Whitten RO, Milner D, et al. The neuropathology of fatal cerebral malaria in malawian children. Am J Pathol. 2011;178:2146-58.

8. Cardoso FL, Brites D, Brito MA. Looking at the blood-brain barrier: molecular anatomy and possible investigation approaches. Brain Res Rev. 2010;64:328-63.

9. Brown H, Hien TT, Day N, Mai NT, Chuong LV, Chau TT, et al. Evidence of blood-brain barrier dysfunction in human cerebral malaria. Neuropathol Appl Neurobiol. 1999;25:331-40.

10. Brown H, Rogerson S, Taylor T, Tembo M, Mwenechanya J, Molyneux $M$, et al. Blood-brain barrier function in cerebral malaria in Malawian children. Am J Trop Med Hyg. 2001;64:207-13.

11. Tasker RC, Acerini CL. Cerebral edema in children with diabetic ketoacidosis: vasogenic rather than cellular? Pediatr Diabetes. 2014;15:261-70.

12. DeMaio L, Rouhanizadeh M, Reddy S, Sevanian A, Hwang J, Hsiai TK. Oxidized phospholipids mediate occludin expression and phosphorylation in vascular endothelial cells. Am J Physiol Heart Circ Physiol. 2006;290:H674-83.

13. Clark IA, Budd AC, Alleva LM, Cowden WB. Human malarial disease: a consequence of inflammatory cytokine release. Malar J. 2006;5:85.

14. Sasi P, Burns SP, Waruiru C, English M, Hobson CL, King CG, et al. Metabolic acidosis and other determinants of hemoglobin-oxygen dissociation in severe childhood Plasmodium falciparum malaria. Am J Trop Med Hyg 2007;77:256-60
15. Lyke KE, Burges R, Cissoko Y, Sangare L, Dao M, Diarra I, et al. Serum levels of the proinflammatory cytokines interleukin-1 beta (IL-1 beta), IL-6, IL-8, IL-10, tumor necrosis factor alpha, and IL-12(p70) in Malian children with severe Plasmodium falciparum malaria and matched uncomplicated malaria or healthy controls. Infect Immun. 2004;72:5630-7.

16. Taylor TE, Borgstein A, Molyneux ME. Acid-base status in paediatric Plasmodium falciparum malaria. Q J Med. 1993;86:99-109.

17. Lee Jl, Burckart GJ. Nuclear factor kappa B: important transcription factor and therapeutic target. J Clin Pharmacol. 1998;38:981-93.

18. Beare NA, Lewallen S, Taylor TE, Molyneux ME. Redefining cerebral malaria by including malaria retinopathy. Future Microbiol. 2011;6:349-55.

19. Taylor TE, Fu WJ, Carr RA, Whitten RO, Mueller JS, Fosiko NG, et al. Differentiating the pathologies of cerebral malaria by postmortem parasite counts. Nat Med. 2004;10:143-5.

20. Dondorp AM, Desakorn V, Pongtavornpinyo W, Sahassananda D, Silamut K, Chotivanich K, et al. Estimation of the total parasite biomass in acute falciparum malaria from plasma PfHRP2. PLoS Med. 2005;2:e204.

21. Fox LL, Taylor TE, Pensulo P, Liomba A, Mpakiza A, Varela A, et al. Histidinerich protein 2 plasma levels predict progression to cerebral malaria in Malawian children with Plasmodium falciparum infection. J Infect Dis. 2013;208:500-3.

22. Potchen MJ, Kampondeni SD, Ibrahim K, Bonner J, Seydel KB, Taylor TE, et al. Neurolnterp: a method for facilitating neuroimaging research on cerebral malaria. Neurology. 2013;81:585-8.

23. Evans AM, DeHaven CD, Barrett T, Mitchell M, Milgram E. Integrated, nontargeted ultrahigh performance liquid chromatography/electrospray ionization tandem mass spectrometry platform for the identification and relative quantification of the small-molecule complement of biological systems. Anal Chem. 2009;81:6656-67.

24. Dehaven CD, Evans AM, Dai H, Lawton KA. Organization of GC/MS and LC/ MS metabolomics data into chemical libraries. J Cheminform. 2010;2:9.

25. Tsao FH, Shanmuganayagam D, Zachman DK, Khosravi M, Folts JD, Meyer $\mathrm{KC}$. A continuous fluorescence assay for the determination of calciumdependent secretory phospholipase A2 activity in serum. Clin Chim Acta. 2007:379:119-26.

26. Schneider: Truncated and censored samples from normal populations. New York: Marcel Dekker, Inc.; 1986.

27. Millard SP. An R package for environmental statistics. New York: SpringerVerlag; 2013.

28. Six DA, Dennis EA. The expanding superfamily of phospholipase $A(2)$ enzymes: classification and characterization. Biochim Biophys Acta. 2000;1488:1-19.

29. Murakami M, Sato H, Miki Y, Yamamoto K, Taketomi Y. A new era of secreted phospholipase A(2). J Lipid Res. 2015;56:1248-61.

30. Nag S, Manias JL, Stewart DJ. Pathology and new players in the pathogenesis of brain edema. Acta Neuropathol. 2009;118:197-217.

31. Dalvi S, Nguyen HH, On N, Mitchell RW, Aukema HM, Miller DW, et al. Exogenous arachidonic acid mediates permeability of human brain microvessel endothelial cells through prostaglandin E activation of EP and EP receptors. J Neurochem. 2015. doi:10.1111/jnc.13117.

32. Fonteh AN, Atsumi G, LaPorte T, Chilton FH. Secretory phospholipase A2 receptor-mediated activation of cytosolic phospholipase A2 in murine bone marrow-derived mast cells. J Immunol. 2000;165:2773-82.

33. Green JA, Smith GM, Buchta R, Lee R, Ho KY, Rajkovic IA, et al. Circulating phospholipase A2 activity associated with sepsis and septic shock is indistinguishable from that associated with rheumatoid arthritis. Inflammation. 1991;15:355-67.

34. Farooqui AA, Litsky ML, Farooqui T, Horrocks LA. Inhibitors of intracellular phospholipase A2 activity: their neurochemical effects and therapeutical importance for neurological disorders. Brain Res Bull. 1999;49:139-53.

35. Ong WY, Farooqui T, Kokotos G, Farooqui AA. Synthetic and natural inhibitors of phospholipases A2: their importance for understanding and treatment of neurological disorders. ACS Chem Neurosci. 2015;6:814-31.

36. Wang P, Li Y, Shao Q, Zhou W, Wang K. Targeting human secretory phospholipase A2 with designed peptide inhibitors for inflammatory therapy. J Drug Target. 2015;23:140-6.

37. Bonventre JV, Nemenoff R. Renal tubular arachidonic acid metabolism. Kidney Int. 1991;39:438-49.

38. Aveldano MI, Bazan NG. Rapid production of diacylglycerols enriched in arachidonate and stearate during early brain ischemia. J Neurochem. 1975:25:919-20. 
39. Vadas P, Taylor TE, Chimsuku L, Goldring D, Stefanski E, Pruzanski W, et al. Increased serum phospholipase A2 activity in Malawian children with falciparum malaria. Am J Trop Med Hyg. 1993;49:455-9.

40. Farooqui AA, Horrocks LA. Phospholipase A2-generated lipid mediators in the brain: the good, the bad, and the ugly. Neuroscientist. 2006; 12:245-60.

41. Griffiths MJ, Ndungu F, Baird KL, Muller DP, Marsh K, Newton CR. Oxidative stress and erythrocyte damage in Kenyan children with severe Plasmodium falciparum malaria. Br J Haematol. 2001;113:486-91.

42. Ferreira A, Balla J, Jeney V, Balla G, Soares MP. A central role for free heme in the pathogenesis of severe malaria: the missing link? J Mol Med (Berl) 2008;86:1097-111.

43. Nanda NK, Das BS. Presence of pro-oxidants in plasma of patients suffering from falciparum malaria. Trans R Soc Trop Med Hyg. 2000;94:684-8.

44. Haorah J, Ramirez SH, Schall K, Smith D, Pandya R, Persidsky Y. Oxidative stress activates protein tyrosine kinase and matrix metalloproteinases leading to blood-brain barrier dysfunction. J Neurochem. 2007;101:566-76.

45. Xi G, Hua Y, Bhasin RR, Ennis SR, Keep RF, Hoff JT. Mechanisms of edema formation after intracerebral hemorrhage: effects of extravasated red blood cells on blood flow and blood-brain barrier integrity. Stroke. 2001;32:2932-8.

46. Xi G, Keep RF, Hoff JT. Erythrocytes and delayed brain edema formation following intracerebral hemorrhage in rats. J Neurosurg. 1998;89:991-6.

47. Bhasin RR, Xi G, Hua Y, Keep RF, Hoff JT. Experimental intracerebral hemorrhage: effect of lysed erythrocytes on brain edema and blood-brain barrier permeability. Acta Neurochir Suppl. 2002;81:249-51.

48. Battison C, Andrews PJ, Graham C, Petty T. Randomized, controlled trial on the effect of a $20 \%$ mannitol solution and a $7.5 \%$ saline $/ 6 \%$ dextran solution on increased intracranial pressure after brain injury. Crit Care Med. 2005;33:196-202.

49. Wakai A, McCabe A, Roberts I, Schierhout G. Mannitol for acute traumatic brain injury. Cochrane Database Syst Rev 2013, 8:CD001049.

50. Kaufmann AM, Cardoso ER. Aggravation of vasogenic cerebral edema by multiple-dose mannitol. J Neurosurg. 1992;77:584-9.

51. Cho J, Kim YH, Han HS, Park J. Accumulated mannitol and aggravated cerebral edema in a rat model of middle cerebral artery infarction. J Korean Neurosurg Soc. 2007;42:337-41.

52. Namutangula B, Ndeezi G, Byarugaba JS, Tumwine JK. Mannitol as adjunct therapy for childhood cerebral malaria in Uganda: a randomized clinical trial. Malar J. 2007;6:138.

53. Mohanty S, Mishra SK, Patnaik R, Dutt AK, Pradhan S, Das B, Patnaik J, Mohanty AK, Lee SJ, Dondorp AM. Brain swelling and mannitol therapy in adult cerebral malaria: a randomized trial. Clin Infect Dis. 2011;53:349-55.

54. Stamatovic SM, Dimitrijevic OB, Keep RF, Andjelkovic AV. Protein kinase Calpha-RhoA cross-talk in CCL2-induced alterations in brain endothelial permeability. J Biol Chem. 2006;281:8379-88.

55. Yu H, Huang X, Ma Y, Gao M, Wang O, Gao T, Shen Y, Liu X. Interleukin-8 regulates endothelial permeability by down-regulation of tight junction but not dependent on integrins induced focal adhesions. Int J Biol Sci. 2013;9:966-79.

56. Aveleira CA, Lin CM, Abcouwer SF, Ambrosio AF, Antonetti DA. TNFalpha signals through PKCzeta/NF-kappaB to alter the tight junction complex and increase retinal endothelial cell permeability. Diabetes. 2010;59:2872-82.

57. Kim JE, Ryu HJ, Choi SY, Kang TC. Tumor necrosis factor-alpha-mediated threonine 435 phosphorylation of p65 nuclear factor-kappaB subunit in endothelial cells induces vasogenic edema and neutrophil infiltration in the rat piriform cortex following status epilepticus. J Neuroinflammation. 2012;9:6.

58. Seydel KB, Fox LL, Glover SJ, Reeves MJ, Pensulo P, Muiruri A, et al. Plasma concentrations of parasite histidine-rich protein 2 distinguish between retinopathy-positive and retinopathy-negative cerebral malaria in Malawian children. J Infect Dis. 2012;206:309-18.

59. Lopera-Mesa TM, Mita-Mendoza NK, van de Hoef DL, Doumbia S, Konate $D$, Doumbouya $M$, et al. Plasma uric acid levels correlate with inflammation and disease severity in Malian children with Plasmodium falciparum malaria. PLoS One. 2012;7:e46424.

60. Orengo JM, Leliwa-Sytek A, Evans JE, Evans B, van de Hoef D, Nyako $\mathrm{M}$, et al. Uric acid is a mediator of the Plasmodium falciparum-induced inflammatory response. PLoS One. 2009:4:e5194.

61. Olivier M, Van Den Ham K, Shio MT, Kassa FA, Fougeray S. Malarial pigment hemozoin and the innate inflammatory response. Front Immunol. 2014;5:25.

62. Mbugi EV, Meijerink M, Veenemans J, Jeurink PV, McCall M, Olomi RM, et al. Alterations in early cytokine-mediated immune responses to Plasmodium falciparum infection in Tanzanian children with mineral element deficiencies: a cross-sectional survey. Malar J. 2010;9:130.

63. Krishnegowda G, Hajjar AM, Zhu J, Douglass EJ, Uematsu S, Akira S, et al. Induction of proinflammatory responses in macrophages by the glycosylphosphatidylinositols of Plasmodium falciparum: cell signaling receptors, glycosylphosphatidylinositol (GPI) structural requirement, and regulation of GPI activity. J Biol Chem. 2005;280:8606-16.

64. Portugal S, Moebius J, Skinner J, Doumbo S, Doumtabe D, Kone Y, Dia S, Kanakabandi K, Sturdevant DE, Virtaneva K, et al. Exposure-dependent control of malaria-induced inflammation in children. PLoS Pathog. 2014; 10:e1004079.

65. Parroche P, Lauw FN, Goutagny N, Latz E, Monks BG, Visintin A, Halmen KA, Lamphier M, Olivier M, Bartholomeu DC, et al. Malaria hemozoin is immunologically inert but radically enhances innate responses by presenting malaria DNA to Toll-like receptor 9. Proc Natl Acad Sci USA. 2007;104:1919-24.

\section{Submit your next manuscript to BioMed Central and we will help you at every step:}

- We accept pre-submission inquiries

- Our selector tool helps you to find the most relevant journal

- We provide round the clock customer support

- Convenient online submission

- Thorough peer review

- Inclusion in PubMed and all major indexing services

- Maximum visibility for your research

Submit your manuscript at www.biomedcentral.com/submit

() Biomed Central 